\title{
NEXT GENERATION ACTIVE BUFFET SUPPRESSION SYSTEM
}

\author{
Stephen C. Galea, Thomas G. Ryall ${ }^{\dagger}$ \\ Defence Science and Technology Organisation \\ Air Vehicles Division, Fishermens Bend \\ Victoria, Australia
}

Robert W. Moses ${ }^{\S}$

NASA Langley Research Laboratory

Hampton, VA, USA

\author{
Edward V. White ${ }^{\S}$ \\ The Boeing Company \\ St. Louis, MO, USA
}

\author{
Douglas A. Henderson* \\ Air Force Research Laboratory \\ Wright-Patterson AFB, OH, USA
}

\author{
David G. Zimcik* \\ National Research Council Canada \\ Ottawa, Ontario, Canada
}

\begin{abstract}
Buffeting is an aeroelastic phenomenon that is common to high performance aircraft, especially those with twin vertical tails like the F/A -18, at high angles of attack. These loads result in significant random stresses, which may cause fatigue damage leading to restricted capabilities and availability of the aircraft. This paper describes an international collaborative research activity among Australia, Canada and the United States involving the use of active structural control to alleviate the damaging structural response to these loads. The research program is being co-ordinated by the Air Force Research Laboratory (AFRL) and is being conducted under the auspices of The Technical Cooperative Program (TTCP). This truly unique collaborative program has been developed to enable each participating country to contribute resources toward a program that coalesces a broad range of technical knowledge and expertise into a single investigation. This collaborative program is directed toward a fullscale test of an F/A-18 empennage, which is an extension of an earlier initial test. The current program aims at applying advanced directional piezoactuators, the aircraft rudder, switch mode amplifiers and advanced control strategies on a fullscale structure to demonstrate the enhanced performance and capability of the advanced active BLA control system in preparation for a flight test demonstration.
\end{abstract}

\section{Introduction}

High performance aircraft, especially those with twin vertical tails like the F/A -18, commonly are subject to an aeroelastic phenomenon called buffeting. These high performance aircraft are, by their very nature, often required to undergo manoeuvres involving high angles of attack. Under these conditions vortices, emanating from the leading edge of the wing and the fuselage, increase the lift on the aircraft as they pass over the wing and the fuselage. However these high energy vortices burst upstream of the empennage causing high energy turbulent flows to impinge on the twin fins and the horizontal stabilator, as shown in Figure 1. The interaction of these substantial buffet loads and the structure cause the structure to resonate. This severe vibrational response is known as buffeting. Prolonged buffeting results in fatigue damage to the vertical fins and horizontal stabilators that may restrict the capabilities and availability of the aircraft. For instance, there is a special inspection for one fighter aircraft that is performed every 200 flight hours to monitor structural damage induced at the root of the vertical stabilizer (referred to here as the vertical tail). This added maintenance decreases the availability of the vehicle and increases its through-life-support costs.

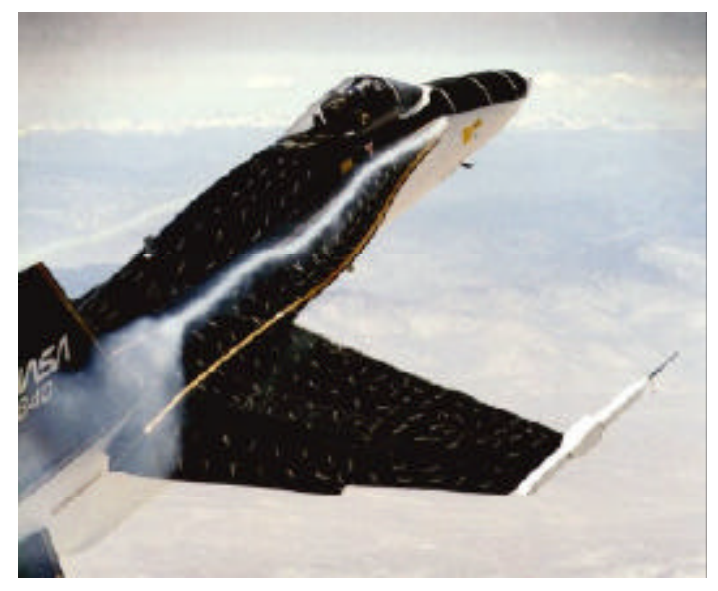

Figure 1. Vortices from the leading edge of a twintail fighter aircraft, generated at high angles of attack, breakdown upstream of the empennage.

For the F/A -18, a significant portion of the fatigue damage on the vertical fins is caused by stresses resulting from the first fin bending and first fin torsional vibration modes (i.e. first and second structural resonant modes, respectively) of the fin. The two flight parameters, angle of attack (AOA) and the dynamic pressure $(\mathrm{Q})$, essentially influence the shape of the frequency response and overall amplitude of resp onse of the fin, respectively. At low AOA, between $10-20$ degrees the vortices impinge on the horizontal stabilator exciting the resonant modes of that structural component. At moderate AOA, about $22-34$ degrees, the vortices impinge on the lower portion of the vertical fin exciting the first torsional mode of the fin, causing damage in the upper portion of the fin as well as the fin root. A significant portion of the damaging stresses in the fin root are caused by the first bending mode of the fin which are excited when vortices generated at high

$\dagger$ Retired

$\S$ Associate Fellow, AIAA

* Senior Member, AIAA 
AOA, above 30 degrees, impinge on the upper portion of the fin.

Design of aircraft to accommodate these buffet loads is a difficult task. Several approaches have been investigated to alleviate the fatigue stresses due to buffeting. One approach is to modify the loadcarrying structure by incorporating passive damping or by increasing the local stiffness of the fin. In the former case a variety of treatments are required to reduce the structural response at specific locations and modes, and over the required operational environments. Constrained layered damping was applied to an F/A-18 horizontal stabilator and resulted in an insignificant increase in structural damping. It was concluded that a substantial (unacceptable) increases in mass would be required to achieve the necessary reduction in structural response. Another approach is to increase the structural stiffness by increasing skin or spar thickness or adding brackets, doublers or cleats. For example the addition of a composite bonded doubler on the outboard skin of the vertical tail of F/A-18A-D aircraft was successful in reducing the fatigue strains in this region and increasing the fatigue life of the aluminium spar of the fin, with a minimal increase in vehicle weight $(\sim 7.2 \mathrm{~kg}){ }^{2}$ However these modifications often result in significant increases in structural weight and transfer the load, and therefore damage, to other locations. Another approach is to alleviate buffet loads by altering the flow field. For example, fences have been attached to the leading edge extensions (LEX) of the F/A-18, where the vortices are generated, in an attempt to reduce buffet loading ${ }^{3,4}$ However, these passive modifications have only limited success since they are only effective at specific flight conditions. A better approach is to combine a number of these passive techniques to increase the fatigue life of components subject to buffeting. For example, on the F/A-18 A-D, the combination of the LEX fence and cleats at the fin root have enabled the fatigue life of the vertical fin to meet the fatigue requirements of the operators.

Since these passive techniques do not fully solve the buffeting problem activities have focused on controlling the structural response by the use of active buffet load control techniques. One method investigated is to use the rudder in conjunction with active control to reduce the buffeting of the F/A -18 fin. ${ }^{5,6}$ This method appears to be effective in controlling buffeting caused by the fundamental bending mode at $15 \mathrm{~Hz}$. Active control systems utilising piezoelectric ceramic (wafer) actuators on a $1 / 6^{\text {th }}$ scale F/A-18 aircraft model in a wind tunnel proved successful at reducing the overall buffeting of the empennage. ${ }^{7,8}$ Therefore, these studies show that the use of active control in conjunction with piezoceramic actuators and the aircraft's rudder to alleviate damaging buffet-induced strain, and increase the fatigue life of vertical tails, is a possible solution to this important design issue. In fact if stresses in the metal attachment points in the root of the vertical tails could be reduced by $10 \%$ then this would double the life of the component.

This issue of buffeting is of particular concern for those countries within The Technical Co-operation Program, (TTCP) that operate F/A-18 aircraft in their fleets, namely Australia, Canada, and the United States. The TTCP is a technical collaboration between the defence laboratories of the United Kingdom, Canada, Australian, United States and New Zealand. Of these countries Australia, Canada and the United States have initiated a collaborative research program aimed at finding a solution to this problem. The organisations involved are the Air Force Research Laboratory (USA), the National Research Council Canada, NASA Langley Research Center (USA) and the Defence Science and Technology Organisation (Australia).

This collaborative program involves tests on a full scale F/A -18 empennage. The initial program of this collaboration involved the use of piezoceramic actuators, bonded to the surfaces of a vertical fin, to provide the means to counter vibrations induced by the buffet loads. Tests conducted in 1998 demonstrated the proof of concept of this technology. ${ }^{9,10,11}$ During the test in 1998, the buffet loads were simulated using powerful electromagnetic shakers and an active buffet load alleviation (BLA) system, using commercially available piezoceramic actuators, linear audio amplifiers and linear time invariant control laws, successfully demonstrated the concept of buffet alleviation in a full-scale aircraft structure. Results of this test indicated that fin fatigue life could be increased significantly thereby adding to the fatigue life of the tail fin. The current collaborative full-scale test program aims to use more advanced piezoelectric actuators, the aircraft rudder and switch mode amplifiers in an optimized system to demonstrate the enhanced performance and capability in preparation for a flight test demonstration.

Due to the complex nature of structural response to buffet loads, advanced methods and expertise from numerous technical disciplines are required to reduce the structural response to extend the life of the aircraft. This international collaboration allowed the coalescence of a broad range of the necessary technical knowledge and expertise into a single investigation enabling a truly unique collaborative program. This paper will elaborate on the interaction and collaboration between the participating countries, through the international program, that has lead to novel developments and benefits many of which were only feasible through the collaborative nature of the program. 


\section{Collaborative Arrangements}

The work share of the two programs "Active Alleviation of Buffeting Using Smart Materials" (stated here as the Initial Program) and "Next Generation Active Buffeting Suppression System" (stated here as the Current Program) was defined such that each participant would be obliged to contribute similar resources toward the program. The general principle was adopted that the results of the activities associated with the program would be shared without restrictions between the three countries. The project agreement documents provided some guidelines that were used to scope the program and outline the sharing of taks. For example, Table 1 illustrates the test agencies and their tasks identified in TTCP agreement PA-2/02/AER "Next Generation Active Buffeting Suppression System".

\section{US Air Force Research Laboratory (AFRL)}

- $\quad$ Project coordination and management

- Contract to Boeing to supply

○ Switch mode amplifiers

○ Rudder actuator

- Flight data

○ Data acquisition system

NASA Langley Research Centre (NASA LaRC)

- LaRC Macro-Fiber Composite piezoelectric actuators

National Research Council Canada (NRC)

- $\quad$ Flight test data

- Switch mode amplifiers

- Controller

Defence Science and Technology Organisation (DSTO)

- IFOSTP rig

- Install F/A -18 test article in rig

- Controller and data acquisition systems

\section{ALL}

- Apply actuators to rig

- Conduct actuator continuity tests

- Open-loop tests

- Update control algorithms

- Closed-loop tests

- Analyse closed-loop data

- Write final report

Table 1. Test agency and their respective responsibilities.

\section{Initial Program}

The full-scale test article was the vertical tail on an F/A-18 structural test article that was inserted into the International Follow-On Structural Testing Project (IFOSTP) $^{12}$ facility at DSTO in Melbourne, Australia. The IFOSTP test rig (Figure 2) has the ability to generate flight representative static and dynamic loads on the airframe including manoeuvre loads, aerodynamic damping, and structural characteristics. The dynamic loads that are applied by the facility, using high-powered high displacement electrodynamic shakers, were measured in flight tests on an F/A-18 aircraft (no manoeuvre loads were applied to the test article during this demonstration). The TTCP team chose to use three different flight conditions, viz., nominal, severe and worst buffet load conditions, that span the conditions through which buffeting occurs - representing relatively low, moderate, and high angles of attack (all above 10 degrees angle of attack) respectively. The amount of time that the aircraft actually spends at these conditions decreased as the angle of attack increases. These conditions were chosen to represent an envelope of flight conditions as well as ensuring that the chosen modes $\left(1^{\mathrm{st}}\right.$ bending and $1^{\mathrm{st}}$ torsion at about $15 \mathrm{~Hz}$ and $45 \mathrm{~Hz}$ respectively) were included in the test environment. In the worst-case buffeting condition, structural responses of up to $100 \mathrm{~g}$ 's RMS are created at the tip of the tail. The loading sequence applied to the test article was developed from data measured in flight tests on a Canadian fighter aircraft.

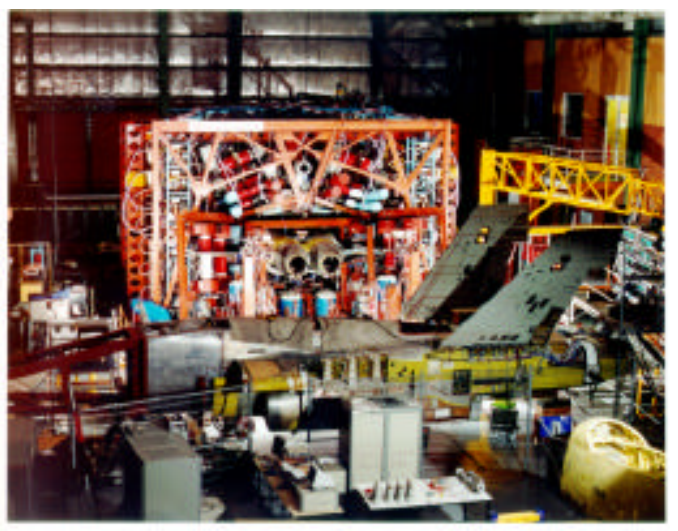

Figure 2. IFOSTP Rig with one F/A-18 structural test article (STO1) inserted and another (FT46) in the foreground.

The active BLA control system, including piezoceramic actuators, sensors, signal conditioners, amplifiers, and a controller, was designed and manufactured specifically for this program by Active Control eXperts, Inc, (ACX), under contract from the U.S. Air Force. Piezoelectric actuators were bonded to the composite skin on both surfaces of the starboard tail as shown in Figure 3. The placement and sizing of the piezoelectric actuators were 
determined using an optimisation scheme that evaluated the modal dilatational strain energy in the tail. $^{13}$ The actuator distribution consisted of wafer stacks of between one to three layers of $0.5 \mathrm{~mm}$ thick piezoelectric ceramic wafers per actuator. The actuators were divided into two groups, determined by a nodal line of the dilatational strain from the two modes of interest, and had a mirror image of actuators attached to the opposite side of the vertical tail. Linear audio power amplifiers were used to drive the piezoelectric ceramic actuators by applying a nominal voltage of about $1500 \mathrm{~V}$ peak-peak $\left(\mathrm{V}_{\mathrm{pp}}\right)$.

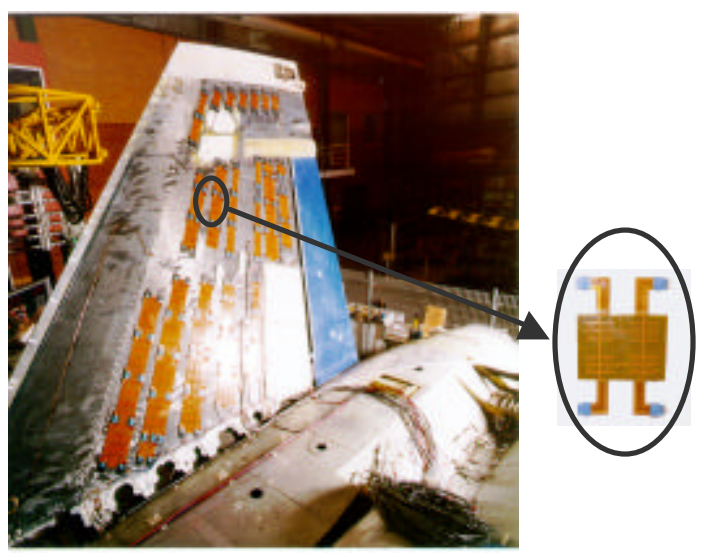

Figure 3. A photograph of the piezoceramic actuators, bonded to the composite skin of an F/A18 fin, used to reduce vibration response of the fin due to simulated buffet.

The sensors that were available included accelerometers (fore and aft at the tip of the fin) and strain gauges (fore and aft at the root). These sensors provided response signals for the feedback control and to monitor the performance of the control system. The hardware configurations were such that only a two-input and two-output feedback control law could be used at any one time. White noise at two frequency bands $10-20 \mathrm{~Hz}$ and $34-52 \mathrm{~Hz}$ were used to excite the fin (to simulate the buffet loads) in order to cover the significant frequency responses centered near $15 \mathrm{~Hz}$ ( $1^{\text {st }}$ bending mode) and $45 \mathrm{~Hz}$ $\left(1^{\text {st }}\right.$ torsion mode).

The open loop (uncontrolled) and closed loop (controlled) tests were completed in October 1997 and February 1998, respectively. The open loop tests allowed the system characterisation that enabled the development of the appropriate transfer functions required in the control laws. The control laws were implemented during the closed loop tests and demonstrated the feasibility of the active BLA control system. The control schemes used in this program were developed in collaboration with each of the three participating countries. The percentage reduction in the rms strain at the trailing edge root of the vertical fin was used as the criterion for assessing the performance of the control strategy.
As indicated above the tests were carried out at a number of different flight conditions. At the nominal flight condition the critical strain was reduced by $51 \%$, while at the penultimate severe flight condition the reduction was $15 \%$. Figure 4 shows a comparison of strain density as a function of frequency between the open loop and closed loop configurations at the nominal flight condition. At the worst flight condition the stresses were reduced by a modest $2 \%$ : this condition is almost the most severe buffet scenario and is a condition which the aircraft spends the least amount of time. Similar reductions occurred in the various accelerometer readings. From these results it is estimated, taking into account usage rates, that if the active BLA system were installed on an F/A-18, the increase in life would be approximately $70 \%$ or in other words, 4000 hours could be added to the life of the tail.

The combination of test facilities, flight data and system components, each from one of the three collaborating counties, clearly illustrated the benefits to be garnered through collaboration where these elements could be shared to achieve the end results.

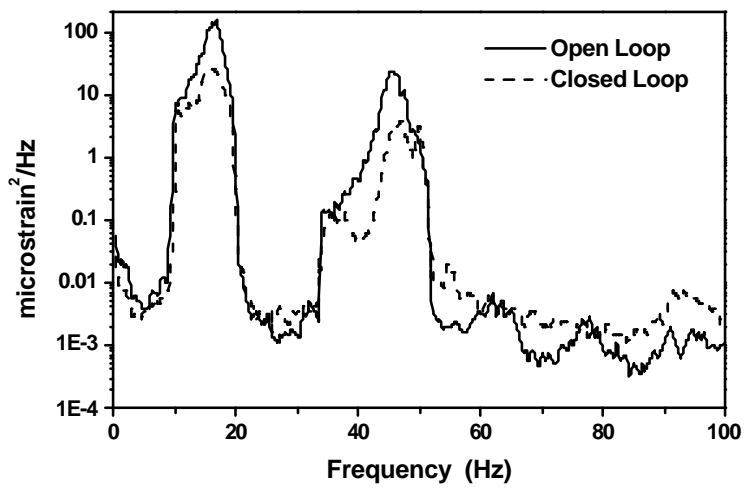

Figure 4. Comparison of open loop and closed loop strain response at the root of the vertical fin for the nominal buffet load condition.

\section{Issues From the Initial Program}

Even though the test was highly successful in demonstrating the effectiveness of the piezoelectric actuators in suppressing the vibration responses of the vertical tail, there were several issues that needed to be resolved for the follow-on test, viz.,
1) Actuator authority
2) Amplifier size
3) Control algorithms
4) Experimental verification of analysis

The first issue was the piezoelectric actuation authority and power requirements. During the initial program it became quite apparent that the actuators used during the test were driven above their 
capability particularly when the tail was excited at the maximum buffet load condition. Also there were a number of actuators that failed during the maximum buffeting condition, it was not determined if the actuators that failed did so because of defects in the actuator (that is a quality assurance issue), environmental degradation or simply close proximity to the shaker attachment where localized strains were potentially higher. In the interim, studies have been conducted to investigate the use of more advanced actuators and amplifiers in order to avoid the problems encountered. Two approaches were eventually followed. The first selected a more advanced actuator system with higher authority for a given excitation voltage and the second developed a blended system that used piezoelectric actuators and an active vertical tail rudder to more evenly spread the control authority requirements between the two.

Also in an effort to achieve typical fighter requirements (minimum size, weight and power) there is a need to reduce size, weight and power requirements of the amplifiers used in the initial tests. In this program 16 large linear audio amplifiers were used which will not achieve present aircraft subsystem requirements. Recent developments in switch mode amplifiers, by Boeing, have led to significant improvements in all these facets - thus allowing significant progress toward a system that can be flight demonstrated.

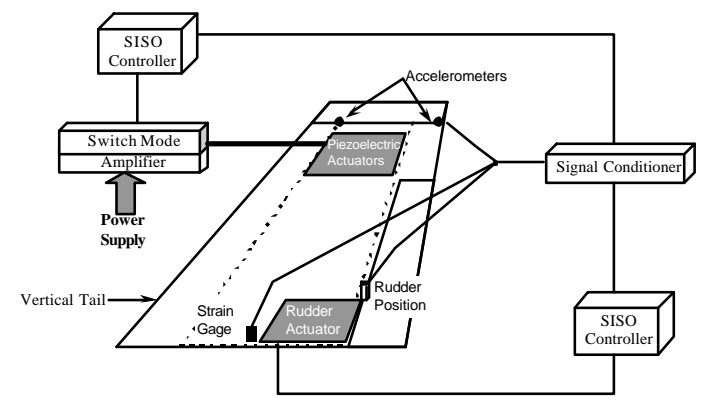

Figure 5. Major components proposed for the advanced BLA control system. ${ }^{15}$

\section{Current Program}

\section{Next Generation Concept}

The closed-loop response using only piezoceramic actuators, as illustrated in Figure 4, shows that this system is more effective in reducing the response of the $2^{\text {nd }}$ resonant mode $\left(1^{\text {st }}\right.$ torsion fin mode at $\left.45 \mathrm{~Hz}\right)$ than the fundamental mode $\left(1^{\text {st }}\right.$ fin bending mode at $15 \mathrm{~Hz}$ ). One reason for this is due to the fact that a significant portion of the modal strain energy in the $2^{\text {nd }}$ mode, is in the skin of the upper third portion of the fin where the surface mounted piezoceramic actuators are located and where their effectiveness is relatively significant due to the relatively low structural stiffness in this region. However a significant portion of the modal strain energy in the fundamental bending mode occurs near the root of the fin, where the piezoceram ic actuators are not as effective due to the significant structural stiffness in this region. Therefore a rudder-piezo actuator "blended" BLA system was investigated experimentally on a 1/6-scale F/A-18 model installed in the Transonic Dynamics Tunnel at NASA LaRC ${ }^{14}$. The program undertaken by NASA LaRC and Boeing used neural predictive controllers as well as time invariant control laws for controlling the rudder, for the first bending, and piezoactuators, for the torsion mode, of the starboard-side fin. This study was followed by a theoretical analysis on a rudderpiezo "blended" system, as shown schematically in Figure 5, and showed 'on paper' the feasibility of such an advanced active BLA control system on a full-scale structure. ${ }^{15}$ The theoretical study also gave an indication of (1) the maximum command rudder position, (2) the number and position of the directional piezoactuators and (3) peak power levels required for the full-scale tests. The study also showed that the primary control force was the rudder inertial force and not the aerodynamic force.

Hence the follow-on ground test program is investigating the use of active control, switch mode amplifiers, with the rudder control surface to control the $1^{\text {st }}$ resonant mode and directional piezoceramic actuators to control the $2^{\text {nd }}$ resonant mode.

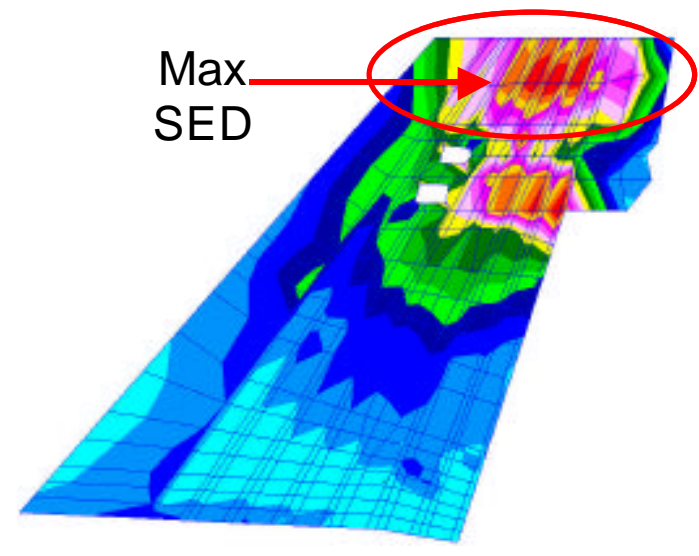

Figure 6. Surface strain energy density (SED) for the 2 nd resonant mode (1st torsion mode) of the fin.

\section{Piezoelectric Actuators}

Based on a system analysis ${ }^{6}$, it was shown that a 60 mil $(1.5 \mathrm{~mm})$ thick multi-layer directional actuator having properties of the LaRC Macro-Fiber Composite (MFC) actuator ${ }^{16,17}$ performed best in suppressing vibration in the second mode of the fin. Figure 6 shows the spatial location on the fin of the MFC actuators used during the finite element analysis. However, it was not certain whether the actuator properties of the MFC (as shown in Figure 7) used in the analysis could be achieved in practice. Also of question was the affordability of the device 
and whether there was a threshold on actuator performance as a function of the number of layers. To answer these questions, NASA conducted an actuator research and development activity whereby numerous prototype stacks were fabricated and tested that consisted of a variety of layers and layer thickness.

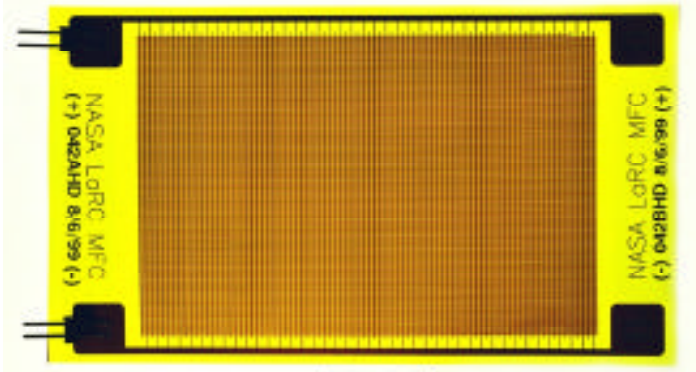

Figure 7. Photograph of NASA LaRC MFC actuator showing the interdigitated electrodes and piezoceramic fibres.

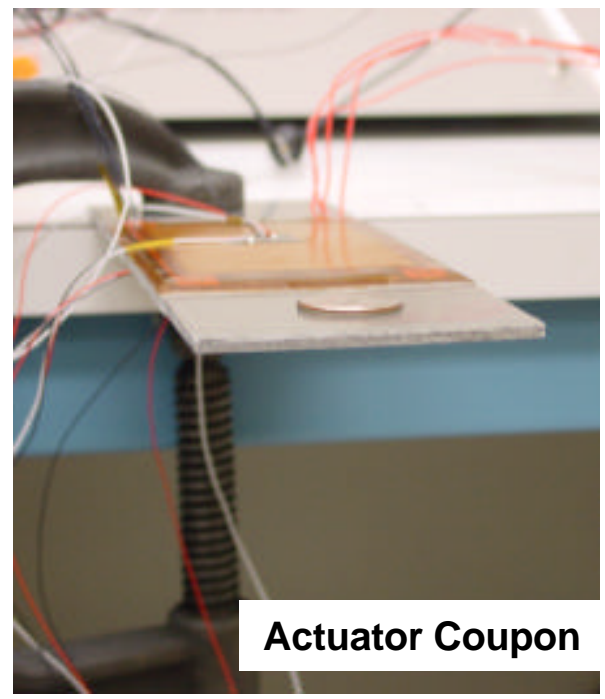

Figure 8. MFC actuator attached to a cantilever aluminium beam.

The experimental set-up for evaluating the performance of the MFC stack actuator configuration is shown in Figure 8. Table 2 lists the actuator configurations that were evaluated. Naturally, the easiest prototype to fabricate was the option consisting of the fewest layers. However, this required the use of the thickest ceramic that did not respond very well to the maximum voltage capability of the amplifier, or at best require voltage levels beyond the range of the amplifier's capabilities to move the device. On the other hand, the most movement per the maximum voltage was achieved using the thinner ceramics; however, many layers would be required to meet the 60-mil thickness that, in turn, drove up the manufacturing cost per stack.

\begin{tabular}{|c|c|c|c|c|}
\hline \multicolumn{5}{|c|}{ List of Candidate Prototypes to Test } \\
\hline \multicolumn{5}{|c|}{ Thickness options to achieve 60 -mil active element } \\
\hline $\begin{array}{c}\text { Option } \\
\text { №. }\end{array}$ & $\begin{array}{l}\text { Thickness } \\
\text { per Layer }\end{array}$ & $\begin{array}{l}\text { Number } \\
\text { of Layers }\end{array}$ & $\begin{array}{c}\text { Total } \\
\text { Thickness }\end{array}$ & $\underline{\text { Comment }}$ \\
\hline 1 & $7 \mathrm{mil}$ & 9 & $63 \mathrm{mil}$ & Stack of MFCs \\
\hline 2 & $9 \mathrm{mil}$ & 7 & $63 \mathrm{mil}$ & \\
\hline 3 & $15 \mathrm{mil}$ & 4 & $60 \mathrm{mil}$ & \\
\hline 4 & $20 \mathrm{mil}$ & 3 & $60 \mathrm{mil}$ & \\
\hline 5 & $30 \mathrm{mil}$ & 2 & $60 \mathrm{mil}$ & Poor \\
\hline 6 & $60 \mathrm{mil}$ & 1 & $60 \mathrm{mil}$ & Performance \\
\hline
\end{tabular}

Table 2. List of the MFC actuator configurations used to determine the most effective actuator stack configuration.

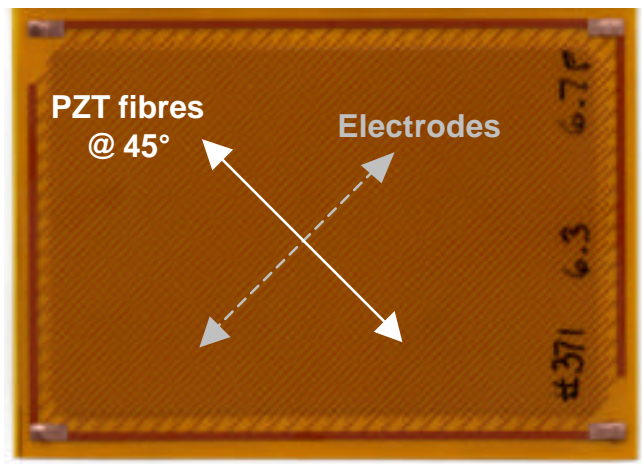

Figure 9. Photograph of NASA LaRC MFC actuator manufactured for the BLA testing program showing the interdigitated electrodes and piezoceramic fibres.

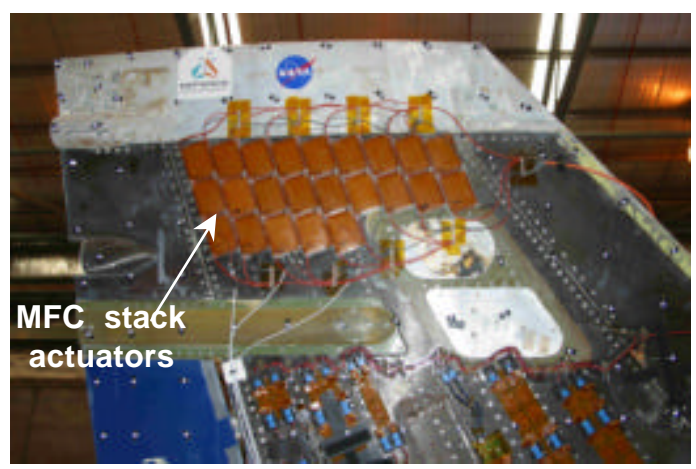

Figure 10. A photograph of NASA LaRC's MFC piezoactuators, bonded to the composite skin of an F/A -18 fin.

To afford the hundreds of layers that this latter option posed required that NASA develop and implement a new manufacturing process. After several modification and trials, a new process was developed that drove the manufacturing cost down from roughly $\$ 230$ per layer to roughly $\$ 5$ per layer. Using this new process, NASA fabricated, verified, and delivered nearly 1000 layers for use by this program. The actuator stack selected by the program consists 
of nine-layers of 7 mil $(0.178 \mathrm{~mm})$ thick ceramic fibres oriented 45 degrees to the longer edge of the actuator packaging, as shown in Figure 9. MFC actuator stacks have been applied to the vertical fins of the test article by NASA LaRC and DSTO personnel, and are shown in Figure 10.

\section{$\underline{\text { Switch Mode Amplifiers }}$}

For high voltage piezoactuators applications the current linear power amplifiers are too large and inefficient to be of practical use in aerospace applications. When linear power amplifiers are driving piezoactuators (i.e. a capacitance load) they dissipate more than double the energy that is transferred to the piezoactuators, and this energy loss increases linearly with increasing frequency. However switch mode amplifiers are able to provide significant higher power to piezoactuators at much better efficiency than similar sized linear drive amplifiers. The main reason for this is due to the fact that switch mode amplifiers do not dissipate such large amounts of power in the output device to drive the reactive loads, since these amplifiers have been designed to account for reactive loads due to the piezoactuators. Therefore, switch mode amplifiers are smaller and have lower power requirement then a similarly rated linear amplifier.

Boeing has developed a number of these amplifiers to drive piezoactuator stacks and piezofibre composite systems to control the shape of helicopter blades and helicopter blade flaps. ${ }^{18,19}$ Systems developed to date have achieved $3 \mathrm{kV}_{\mathrm{pp}}$ at $0.2 \mathrm{amps}, 2 \mathrm{kV}_{\mathrm{pp}}$ at $1 \mathrm{amp}$ and $1.5 \mathrm{kV}_{\mathrm{pp}}$ at $8 \mathrm{amp}$.

Based on this knowledge and expertise AFRL has contracted Boeing to design, build and supply switch mode amplifiers for the current program of work on the advanced BLA control system. The switch mode amplifiers developed for this program are nominally rated at $3.0 \mathrm{kV}_{\mathrm{pp}}$ at $2 \mathrm{amp}$. Two amplifiers will be used, each amplifier will be used to drive banks of MFC actuators on each side of the tail. These systems have been tested during an initial tes ting program at NASA LaRC. The amplifiers were driven successfully up to a maximum value of $90 \%$ of full power during the sine dwell testing.

Load conditions

Four types of load conditions are being developed for application during the closed loop test phase of the testing program. These conditions are based on the following requirements:

(1) Maximum fin tip response condition (plus representative manoeuvre loads);

(2) Maximum fatigue damage at fin root condition (plus representative manoeuvre loads);

(3) Buffet sequence application (varying target buffet and manoeuvre load);

(4) Broadband dynamic load application.

The target dynamic responses for these different load cases are then scaled to various levels and with different manoeuvre loads where appropriate to provide a number of options during the testing program. Each sequence will nominally have a duration of 30 seconds. Note in this program it is intended to also apply the manoeuvre loads, as opposed to the initial program where only dynamic loads were applied, thus this program will evaluate the performance of the control laws and the actuators under as realistic flight conditions as possible. Time varying dynamic and manoeuvre loading sequences, see requirement (3), are also being develop to evaluate fully the control laws. These sequences will have the following characteristics:

- Both manoeuvre and target dynamic loading varying;

- Constant manoeuvre/varying target dynamic loads; and

- Varying manoeuvre/constant target dynamic loads.

The buffet loads are nominally applied by using two narrow bands, viz., Band 1 frequency bandwidth of $10-20 \mathrm{~Hz}\left(1^{\text {st }}\right.$ Bending) and for the Band 2 frequency bandwidth of $34-52 \mathrm{~Hz}$ ( $1^{\text {st }}$ Torsion). Therefore, in order to fully evaluate control laws condition (4) will also be applied. A broadband flat force spectrum will be applied with a bandwidth of $10-60 \mathrm{~Hz}$. This condition will achieve a considerably lower maximum buffet load condition then that achieved by the two-narrowband bins. Hence in this case it is expected that the fin tip response will be considerably lower then that achieved by load conditions (1) - (3).

System Identification

A precursor to designing any control law (for a system of any complexity) is to have a mathematical model of the system that has to be controlled. A very common model is an LTI (linear time invariant) system. Even though the system to be controlled may be non-linear, as is known to be the case with the F/A-18 empennage in the IFOSTP rig, then an LTI description may still be adequate provided that the system is identified around the "normal" operating condition. This requires the system identification to take place with all controls working simultaneously as well as with the external disturbance (simulated buffet) being applied. LTI systems are best identified using sufficiently rich (in spectral content) and persistently exciting input signals. Typical inputs are band limited white noise or frequency sweeps. There are two controls in the test, one voltage to rotate the rudder the other to activate the piezoelectric ceramic actuators.

Ideally maximum likelihood estimation procedures should be used so as to extract the best possible class of state space representation. However maximum likelihood estimation is a highly non-linear problem and as a result a local solution may be found rather than a global one. Using Singular Value Decomposition (SVD) applied either to frequency 
response data, impulse responses or to the original time series, this problem can be averted and a state space representation found. It is further proposed that these estimates are used as initial estimates in a maximum likelihood method.

All programs in this section used Matlab. The data acquisition system uses both dSpace and Matlab. Although a lot of programs were designed from first principles extensive use will be made of the Matlab toolboxes, Robust Control and System Identification.

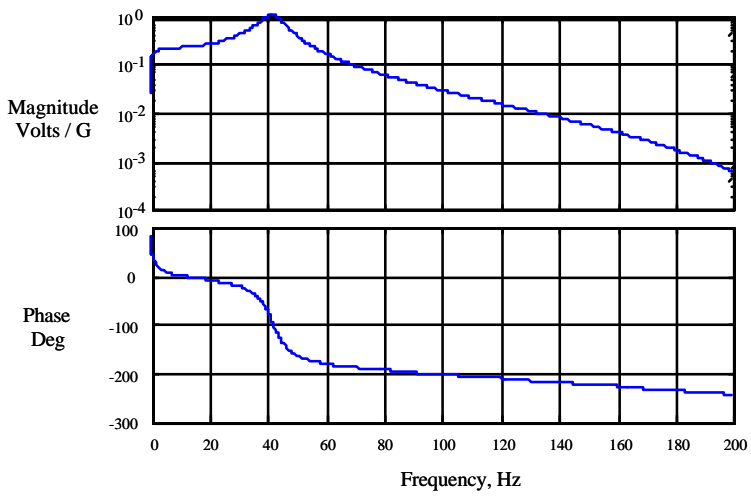

Figure 11. Frequency response functions of typical control laws for the fin

Control

\section{NASA LaRC}

The approach taken by NASA for control of the fin subjected to buffet loads is to increase the damping when possible. Fundamentally, this approach works very well for lightly damped structures. The total damping in mode 2 (shown in Figure 6) remains fairly low during buffet, a suitable condition for implementing this approach. Another factor that must be considered in the design of the control law is the total power being requested of the drive or power electronics to move the actuators in a prescribed fashion that is dictated by the control law. One way to focus the power of the amplifier into the mode of interest is by including some filtering in the control law itself. Other ways that are implemented whenever possible are choice of sensor location and analogue filtering outside the controller. However, these other means to limit the power may pose additional and unfavourable constraints and thus are not considered in the present design. The sensor selected for the present design is an accelerometer located near the trailing edge tip of the fin. The acceleration is fed through the control law, shown in Figure 11, where it is filtered, gained, and phased. The output of the controller is then fed into the amplifiers after application of an appropriate gain factor.

\section{$\underline{\text { DSTO }}$}

From DSTO's perspective, there are a number of standard approaches which will, time permitting, be tried. These include the linear quadratic regulator, pole assignment, and robust approaches such \& $\mathrm{H}$ infinity design. The linear quadratic regulator balances control energy against output energy. Pole assignment assigns the closed loop poles to desirable locations. In this problem the closed loop poles should be more heavily damped than the open-loop poles. Designs like $\mathrm{H}$-infinity control try to minimise worst possible cases. Very simple control laws like Proportional, Differential, and Integral (PDI) might also be tried.

One novel approach that is to be applied is to increase the damping of the closed-loop poles as much as possible subject to a control energy constraint (pre-specified) and further subject to the controller's poles being constrained to a certain region.

\section{$\underline{\mathrm{NRC}}$}

Based on past experience, a Linear Quadratic Gaussian (LQG) regulator will be implemented as the initial control system. The regulator will be designed for performance in the response bandwidth with roll off at lower and higher frequencies. The control effort and the amplitude reduction will be investigated as the metrics to evaluate the control system performance. Robustness of the control system to reject disturbance under the different flight conditions will be investigated.

\section{Benefits of collaboration}

The overall goal is to flight trial this system to illustrate its effectiveness; however, the system needs to be fully ground tested before installing for flight trials. By combining the talents and resources available through TTCP, we are conducting the most realistic and cost-effective ground validation test of the hardware possible. The collaboration has enabled the following significant benefits.

1) High concentration of expertise achieved:

- Compressed time required for discovery

- Encouraged "real time" problem solving

- Engaged technical interaction

Each country brought major unique technical elements, already in place, that complemented those of the others. The collaboration enabled a unique combination of complementary skills, experience and testing facilities that would be difficult and risky to duplicate elsewhere for productive research in a timely, efficient and cost effective manner. The Australians have the unique IFOSTP test rig for simulating realistic flight dynamic loads on the actual airframe at multiple points simultaneously; the Canadians conducted the flight tests for building a database of flight loads from which IFOSTP was developed; the US had the experience and knowledge 
with designing, fabricating, integrating and testing piezoceramic actuators and switching mode amplifier technologies into hardware developed under other aerospace programs.

The collaboration also encouraged "real time" problem solving to compress the time for technical discovery and stimulated interaction.

2) Single test approach achieved:

- Unified objectives

- Created common understanding of problem

- Allowed direct comparison of control approaches

- Avoided parochial views to be established

- Disseminated data uniformly to all participants

The use of the IFOSTP test rig fostered the development of a unified objective for the participants. This allowed all of the participants to come to a common understanding of the problem avoiding any parochial views to be formed. This then permitted the participants to make direct comparison of all of the control approaches and view them from a more equal perspective. This was made possible also because the data were equally shared for better comparison.

The single test approach also allowed clear economic advantages, such as:

- Costs are shared between the three countries thus making this project economically viable;

- Shared facilities and resources have achieved maximum economic benefit and a considerable multiplier effect;

- The use of facilities and expertise already obtained enabled a complete substantial program without duplication of costs in the member countries

3) The collaboration achieved timely and cost effective scientific and technical solutions for the following technical issues:

- Unaccounted forces during the system characterisation stage

- Control algorithm development aid

- Optimization of actuator placement

- "Real world" fatigue loading spectra development

One example where collaboration was most effective started with the initial open-loop test phase of the initial test. As the data were being processed and analysed it was found that the data was not correlating well with the analytical predictions. Upon closer scrutiny and additional testing it was discovered that the analysis had not accounted for the effects of the shaker on the vertical tail response due to frictional damping and modal response frequencies. However with the group of experts analysing the data a solution was quickly found that allowed the overall characterization of the F/A -18 vertical fin to proceed within the short time window allowed. This issue provided greater insight, for all participants, into the problems associated with trying to simulate the buffet response.

\section{Conclusions}

Due to the complex nature of structural response to buffet loads, advanced methods and expertise from numerous technical disciplines are required to reduce the structural response to extend the life of the aircraft. This truly unique international collaborative program allows the development and demonstration of the advanced BLA system to be undertaken through the coalescence of a broad range of the necessary technical and scientific knowledge and expertise - a task which would not have been technically and economically feasible for one country to undertake. The interaction and collaboration between the participating countries, through the international program, has lead to novel developments and benefits many of which were only feasible through the collaborative nature of the program. The initial program showed the feasibility of using active BLA system as a means of reducing the buffeting experienced by modern high performance fighter aircraft. The current program aims at applying advanced directional piezoactuators, the aircraft rudder, switch mode amplifiers and advanced control strategies on a full-scale structure to demonstrate the enhanced performance and capability of the advanced active BLA control system in preparation for a flight test demonstration.

\section{Acknowledgements}

The authors gratefully acknowledge that the continued successes in the development and demonstration of the active BLA control system on a full-scale aircraft structure are due to the dedication, knowledge and expertise of numerous people from the following organisations:

- $\quad$ Air Force Research Laboratory (USA) ;

- NASA Langley Research Centre;

- National Research Council Canada;

- Defence Science and technology Organisation (Australia);

- Boeing;

- Active Control eXperts Inc.;

- CSA Inc.

\section{Reference}

1 Goldman, A., Piperias, P. and Rider, C.D. "Dynamic tests on an F/A-18 Stabilator", Aeronautical Research Laboratory, Aircraft Structures Technical Memorandum 535, June 1990.

2 Ferman, M. A., Liguore, S. L., Colvin, B. J., and Smith, C. M., "Composite 'Exoskin' doubler extends F-15 vertical tail fatigue life," 34th AIAA Structures, Structural Dynamics, and Materials Conference, La Jolla, CA, 19-22 April 1993. 
3 Pettit, C. L., Banford, M., Brown, D., Pendleton, E., "Full-scale wind-tunnel pressure measurements on an F/A-18 tail during buffet," Journal of Aircraft, Volume 33, Number 6, November-December 1996, pp. 1148-56.

4 Meyn, L. A. and James, K. D., "Full-scale windtunnel studies of F/A-18 tail buffet," Journal of Aircraft, Volume 33, Number 3, May -June 1996, pp. 589-95.

5 Pado, L E. and Lichtenwalner, P. F., "Neural Predictive Control for Active Buffet Alleviation," AIAA-99-1319, 40th AIAA Structures, Structural Dynamics, and Materials Conference, St. Louis, MO, 12-15 April 1999.

6 J. K. Burnham, D. M. Pitt, E. V. White, D. A. Henderson and R. W. Moses, An Advanced Buffet Load Alleviation System, 42nd AIAA/ASME/ ASCE/AHS/ASC Structures, Structural Dynamics, and Materials Conference, Seattle, Washington, AIAA 2001-1666, April 16-19, 2001, pp. 10

7 Moses, R. W., “Vertical Tail Buffeting Alleviation Using Piezoelectric Actuators - Some Results of the Actively Controlled Response of Buffet-Affected Tails (ACROBAT) Program," SPIE's 4th Annual Symposium on Smart Structures and Materials, Industrial and Commercial Applications of Smart Structures Technologies Conference, San Diego, CA, 4-6 Mar 97.

8 Lazarus, K. B., Saarmaa, E., and Agnes, G. S., "An Active Smart Material System for Buffet Load Alleviation," Proceedings from SPIE's 2nd Annual International Symposium on Smart Structures and Materials, Volume 2447, 1995, pp. 179-192

9 Hopkins, M., Henderson, D., Moses, R., Ryall, T., Zimcik, D., and Spangler, R., "Active Vibration Suppression Systems Applied to Twin Tail Buffeting," Smart Structures and Materials 1998: Industrial and Commercial Applications of Smart Structures Technologies, Editor(s): Sater, Janet M. Proceedings of SPIE Vol: 3326 pp27-33, San Diego, CA.

10 T.G. Ryall, R.W. Moses, M.A. Hopkins, D Henderson, D.G. Zimcik and F. Nitzsche $2^{\text {nd }}$ Australasian Congress on Applied Mechanics Canberra 1999 Buffet Load Alleviation.

11 D.A. Henderson, M.A. Hopkins, R.W. Moses, D. Zimcik \& T.G. Ryall International Forum on Aeroelasticity and Structural Dynamics Conference. Williamsburg USA July 1999 Vibration Control systems for Buffet Load Alleviation

12 Conser, D. P., Graham, A. D., Smith, C. J., and Yule, C. L., "The Application of Dynamic Loads to a Full-Scale F/A-18 Fatigue Test Article," 20th Congress of the International Council of the
Aeronautical Sciences (ICAS), Sorrento, Napoli, Italy, 8-13 September 1996, ICAS-96-5.10.5, Volume 2, pp. 2465-2480.

13 Moore, J. W., Spangler, R. L., Lazarus, K. B., and Henderson, D. A., "Buffet Load Alleviation Using Distributed Piezoelectric Actuators," Symposium on Adaptive Structures, ASME International Mechanical Engineering Congress and Exposition, Atlanta, GA, November 1996.

14 Robert W. Moses, Contributions to Active Buffeting Alleviation Programs by the NASA Langley Research Center, 40th AIAA/ASME/ ASCE/AHS/ASC Structures, Structural Dynamics, and Materials Conference, St. Louis, Missouri, AIAA 99-1318, April 12-15, 1999.

15 Jay K. Burnham "Active Vibration Suppression Technology Buffet Load Alleviation (BLA) Program" US Air Force Research Laboratory, AFRL-VA-WP-TR-2002-3002, June 2001.

16 W. Keats Wilkie, R. G. Bryant, J. W. High, R. L. Fox, R. F. Helbaum, A. Jalink, Jr., B. D. Little, and P. H. Mirick, "Low-Cost Piezoelectric Actuator for Structural Control Applications," SPIE's 7th International Symposium on Smart Structures and Materials, Newport Beach, California, March 5-9, 2000

17 Robert W. Moses, Carol D. Wieseman, Aaron A. Bent and Alessandro E. Pizzochero, Evaluation of New Actuators in a Buffet Loads Environment, SPIE's 8th International Symposium on Smart Structures and Materials, Newport Beach, California, March 48, 2001

18 D. J. Clingman and M. Gamble, "High voltage switching piezo drive amplifier", SPIE 6th Annual International Symposium on Smart Structures and Materials, March 1-4, 1999. Newport Beach CA.

19 D. J. Clingman, "High power piezo drive amplifier for large stack and PFC applications", SPIE 8th Annual International Symposium on Smart Structures and Materials 2001: Smart Electronics and MEMS, Vol 4334, March 1-4, 2001. Newport Beach CA. pp $345-353$. 